\title{
Family doctor-driven follow-up for adult childhood cancer survivors supported by a web-based survivor care plan
}

\author{
R. Blaauwbroek • H. A. Barf • K. H. Groenier • \\ L. C. Kremer • K. van der Meer • W. J. E. Tissing • \\ A. Postma
}

Received: 3 October 2011 / Accepted: 31 October 2011 /Published online: 29 November 2011

(C) The Author(s) 2011. This article is published with open access at Springerlink.com

\begin{abstract}
Purpose To facilitate family doctor-driven follow-up for adult childhood cancer survivors, we developed a survivor care plan (SCP) for adult survivors and their family doctors. Methods The SCP was accessible for survivors and their family doctors on a secure website and as a printed booklet. It included data on diagnosis, treatment and potential risks as well as recommendations for follow-up. Childhood cancer survivors who were off-treatment $\geq 5$ years, aged $\geq 18$ years and not involved in a long-term follow-up program were eligible. They were advised to visit their family doctor. The endpoints were numbers of participants, adherence of family doctors to the guidelines and satisfaction ratings.
\end{abstract}

R. Blaauwbroek · W. J. E. Tissing · A. Postma

Department of Paediatric Oncology, University Medical Center Groningen (UMCG), University of Groningen,

Groningen, The Netherlands

\section{H. A. Barf}

Directorate of Medical Affairs, Quality and Safety, University Medical Center Groningen (UMCG), University of Groningen, Groningen, The Netherlands

R. Blaauwbroek $\cdot$ K. H. Groenier $\cdot$ K. van der Meer Department of General Practice, University Medical Center Groningen, University of Groningen,

Groningen, The Netherlands

\section{C. Kremer}

Department of Paediatric Oncology, Emma Children's Hospital, Amsterdam, The Netherlands

R. Blaauwbroek $(\bowtie)$

Division of Paediatric Oncology, Department of Paediatrics, University Medical Center Groningen, University of Groningen, Hanzeplein 1, P.O. Box 30 001, 9700 RB,

Groningen, The Netherlands

e-mail: h.kruyt@filternet.nl
Results The eligibility criteria were fulfilled by 108 survivors. Three family doctors and 15 survivors refused, 10 survivors were non-responders. Of the remaining 80 survivors, 73 survivors visited 72 family doctors. Sixtynine $(96 \%)$ family doctors returned data of whom $60(83 \%)$ fully adhered to the recommended tests. The majority of survivors and family doctors were satisfied about the SCP. Conclusions A (web-based) SCP for survivors and family doctors can serve as an effective communication vehicle to provide adequate shared care by the long-term follow-up clinic and family doctors.

Keywords Childhood cancer survivors · Survivor care plan $\cdot$ Long-term follow-up $\cdot$ Family doctors

\section{Introduction}

Survivors of childhood cancer are at risk of long-term morbidity and have an increased risk of mortality. Two thirds of long-term childhood cancer survivors have one or more chronic health problems, while $40 \%$ have severe problems, requiring medical surveillance or treatment [13]. Whereas nowadays it is generally accepted that longterm follow-up of these survivors is essential for detection and treatment of late complications at an early stage, there are still adult survivors from the past who do not yet participate in long-term follow-up.

World-wide and recently also in The Netherlands, guidelines have been developed to address the need for long-term follow-up (www.survivorshipguidelines.org; www.sign.ac.uk; www.ukcesg.org; www.skion.nl). However, there is no consensus about the best way to organise this follow-up care for adult long-term childhood cancer survivors. 
Several models of long-term follow-up care have been proposed [4-6]. Goldsby identified four models of longterm follow-up care, namely a patient-driven, a primary care provider-driven, a paediatric oncologist-driven and an adult medicine-driven program. All these models have advantages and disadvantages. Wallace et al. [6] suggested that follow-up should be organised into three levels according to a patient's individual risk profile. Despite these proposals, many adult survivors still have no regular follow-up, receiving problem-driven medical care from their family doctors [7]. Those being followed are predominantly seen at paediatric oncology clinics, often even long into adulthood. This policy cannot be sustained in the future as the population of survivors increases and ages. Moreover, paediatric oncologists are not the most appropriate health care providers for delivering care to adult survivors. Transition to adult health care providers is needed when the childhood cancer survivor reaches adulthood. However, it is difficult to identify the best possible health care worker to provide this follow-up care, since the survivors may have ongoing complex health needs and co-morbidities that require many different approaches. A good alternative might be the family doctor. In The Netherlands, almost everyone has health care access through a national health plan and survivors usually have a family doctor. Moreover, family doctors already have cooperation with specialists in the shared care for other complex health conditions, as diabetes, coronary artery disease, heart failure and COPD. Lastly, the necessary tests are no problem, since many medical tests, i.e. blood tests, echocardiography, spirometry or bone density measurement, can be requested by family doctors without the intervention of a specialist.

For the transition from the paediatric oncologist to the family doctor, the collaboration between the two professionals is essential, which might be guaranteed by a sharedcare model. This has been shown in adult cancer patients, for whom several studies showed that they are willing to consider follow-up by their family doctor as an alternative to hospital-based care [8-10]. Moreover, in an earlier study, we showed that shared care by paediatric oncologists and family doctors is feasible for the follow-up of adult longterm survivors [11]. Nearly $90 \%$ of the survivors and $80 \%$ of the family doctors were satisfied with this shared-care model. However, our previous study showed also that the exchange of information between the long-term follow-up clinics and the family doctors should be improved. A survivor care plan (SCP) has been recommended for cancer survivors to improve communication between the survivor, the oncologist and the family doctor [12-17]. Survivors are interested in a SCP; it has been shown that many patients are interested in having access to their own medical record, whether or not electronic [18].
Recently, Oeffinger et al. [19] studied the feasibility of a mailed one-page SCP to promote risk-based screening among high-risk Hodgkin lymphoma survivors who are no longer followed at a cancer centre. They showed that the self-reported rates of mammogram and echocardiogram screening among high-risk survivors of childhood Hodgkin lymphoma increased. Survivors were encouraged to discuss the SCP with their family doctor.

We conducted a study on a SCP with a family doctor-driven design. We developed a personalised web-based SCP for follow-up care, accessible for the adult survivors of childhood cancer themselves as well as for their family doctors. We studied the usefulness of this personalised SCP by evaluating the adherence of family doctors to the guidelines, and furthermore, we studied the experiences of survivors and family doctors who used the (web-based) SCP for information.

\section{Patients and methods}

\section{Participants}

In the University Medical Centre Groningen (UMCG), care for long-term childhood cancer survivors is provided by a dedicated long-term follow-up clinic (LTFU), which was initiated in 1995. Prior to the start of this LTFU clinic, patients were usually discharged after a disease-free interval of 5-10 years. Up to 2004 , the total population of 5 -year non-CNS tumour survivors was 807 and 566 of them were involved in regular follow-up. At that time, patients with tumours of the central nervous system were being followed by an independent multidisciplinary neuro-oncology team. In 2004, we started to trace and recall the remaining 241 survivors who did not yet participate in any follow-up program, as far as we knew. Patients with tumours of the central nervous system, who were followed by a multidisciplinary neuro-oncology team, were not eligible. Survivors were traced with help of the municipal administration, and if there were doubts if they were still alive, we contacted their family doctor. In an earlier study in 2004 , a random sample of 133 of these survivors was recalled and 123 participated (10 lost to follow-up) in a shared-care followup program with family doctors [11]. The present study started in September 2008 and was designed for the benefit of the remaining survivors, who also belonged to the group of survivors who had been discharged before 1995 and who had not been recalled to the long-term follow-up clinic yet. Participants in the 2004 study were significantly younger at the start of study compared with participants in the present study ( 34 vs 38 years, $p=0.007$ ), and time since diagnosis was significantly shorter ( 26 vs 29 years, $p=0.015$ ). There were no significant differences in gender, age at diagnosis, and initial diagnosis. 
Eligibility criteria of this study were: current age of 18 years or older, previous treatment for childhood cancer at the Department of Paediatric Oncology of the UMCG, The Netherlands, at least 5 years off-treatment, no mentally handicapped and not yet being involved in any late effects follow-up program elsewhere. No selection was made on the base of the individual risk profile related to the survivor's cancer history.

Survivors were categorized in a three-level risk model on the basis of their cancer history. According to Wallace et al. [6], survivors at low-risk level (level 1) and medium-risk survivors (level 2) could be managed in primary care, while high-risk survivors (level 3) would need annual follow-up in a late effects clinic. In our study, survivors of all three levels were managed in primary care.

Procedure and development of a web-based survivor care plan

Eligible survivors received an information letter about the potential risks of late effects and the desirability of longterm follow-up. Two weeks later, the possibility of followup by the family doctor and details of the online SCP were explained by telephone by a paediatric oncologist (AP) and the survivor was invited to participate in this family doctordriven follow-up. If the survivor and his/her family doctor agreed, we constructed a personalised SCP. This plan consisted of detailed online information regarding the patient's cancer and treatment history, risks for potential late effects, recommendations for future follow-up and advice about a healthy lifestyle (based on the recently developed Dutch DCOG LATER guidelines; www.skion.nl). An example of a SCP is presented in Fig. 1.

This personalised SCP was made available on a secure website to the survivors and to their family doctors, who were provided by e-mail with a username and a password. To the survivors, the SCP was also supplied as a printed booklet.

Survivors were asked to make an appointment of at least half an hour with their family doctor, and they were advised to bring the printed SCP with them. After 6 months, an e-mail reminder was sent to the survivors who had not yet planned a late effects-related visit by their family doctor. Family doctors were asked to return the results of the planned screening, either by filling in the online form or the printed form provided with a stamped addressed envelope. Written consent for the web-based exchange of their medical data was obtained from all participants.

To secure confidentiality, the personalised SCP did not contain personal items such as names or addresses from the survivors; instead, age in years and a serial number were used for identification. As the study was meant to provide recommended health care to survivors who were not yet involved in any kind of follow-up and implementation of the recently developed national guidelines for long-term follow-up of childhood cancer survivors, the Ethics Committee considered that no approval was required.

Late effects that were reported by the family doctors were graded using the Common Terminology Criteria for Adverse Events (version 4.0) [20]. Grade 1 effects are small and usually asymptomatic. Grade 2 effects are moderate but do not impair daily activities. Grade 3 effects are severe and need more serious interventions. Grade 4 effects are potentially life threatening.

Evaluation of the web-based survivor care plan

The SCP and the screening by the family doctor were evaluated by using an 18-item questionnaire for the survivors and a 14-item questionnaire for the family doctors. The questionnaire included items on accessibility and user friendliness of the website, and degree of satisfaction with the provided information: in addition, the survivors were asked whether negative memories were triggered. Items could be answered on a four-point scale (strongly agree, agree, disagree, strongly disagree), and there was an option for 'no opinion/not applicable'. For the analysis, the answers were dichotomized to 'agree' or 'disagree'.

\section{Statistical analysis}

Data were analysed by descriptive methods. No additional statistical tests were performed. Descriptive analyses were done with SPSS for Windows (version 15).

\section{Results}

Participants

Eighty of the 108 eligible survivors and 79 family doctors (1 family doctor had 2 patients) participated. Ten survivors were lost to follow-up, 3 family doctors refused and 15 of the invited survivors refused to participate, mostly because they felt healthy and did not wish to look back; they stated that they had made a new start in life (Fig. 2). Five bone tumour survivors were included who were over 18 years at diagnosis and had been treated on paediatric oncology protocols at the Department of Paediatric Oncology. Characteristics of the participating survivors are shown in Table 1 . Within the first year of the study, $73 / 80$ survivors had visited 72 family doctors and 7 had not for various reasons, such as moving abroad $(n=1)$, serious medical complications requiring specialist outpatient appointments $(n=4)$ and unknown $(n=2)$. These seven patients did agree 
Fig. 1 Example of two pages of the website

\begin{tabular}{|c|c|c|}
\hline UmCG & \multicolumn{2}{|c|}{ * Life after childhood cancer } \\
\hline \multicolumn{3}{|l|}{ Patient information } \\
\hline \multirow{13}{*}{$\begin{array}{l}\text { Short overview } \\
\text { Diagnosis } \\
\text { Chemotherapy } \\
\text { Radiotherapy } \\
\text { Other treatments } \\
\text { Important complications } \\
\text { Late effects } \\
\text { Diagnostic tests } \\
\text { Guidelines } \\
\text { Screenings form }\end{array}$} & \multicolumn{2}{|l|}{ Chemotherapy } \\
\hline & Treatment dates & $11-06-2003$ till $14-11-2003$ \\
\hline & Amsacrine IV & $500.0 \mathrm{mg} / \mathrm{m}^{2}$ \\
\hline & L-Asparaginase IV & $12000.0 \mathrm{E} / \mathrm{m}^{2}$ \\
\hline & Corticosteroids & \\
\hline & $\begin{array}{l}\text { Prednisone } \\
\text { DAF intrathecally }\end{array}$ & \\
\hline & Cytarabine & \\
\hline & - Cytarabine iv standard dose & $4662.0 \mathrm{mg} / \mathrm{m}^{2}$ \\
\hline & $\begin{array}{l}\text { - Cytarabine iv high dose } \\
\text { - Cytarabine inthratecally }\end{array}$ & $30000.0 \mathrm{mg} / \mathrm{m}^{2}$ \\
\hline & Daunorubicin IV & $300.0 \mathrm{mg} / \mathrm{m}^{2}$ \\
\hline & Etoposide IV & $1500.0 \mathrm{mg} / \mathrm{m}^{2}$ \\
\hline & Methotrexate & \\
\hline & $\begin{array}{l}\text { - Methotrexate intrathecally } \\
\text { Mitoxantrone IV }\end{array}$ & $50.0 \mathrm{mg} / \mathrm{m}^{2}$ \\
\hline
\end{tabular}

\begin{tabular}{|c|c|}
\hline UmCG & * Life after childhood cancer \\
\hline $\begin{array}{l}\text { Short overview } \\
\text { Diagnosis } \\
\text { Chemotherapy } \\
\text { Radiotherapy } \\
\text { Other treatments } \\
\text { Important complication: } \\
\text { Late effects } \\
\text { Diagnostic tests } \\
\text { Guidelines } \\
\text { Screenings form } \\
\end{array}$ & $\begin{array}{l}\text { Guidelines } \\
\text { Risk of heart damage } \\
\text { There is a risk for cardiac dysfunction after treatment with } \\
\text { anthracyclines and mitoxantrone. } \\
\text { Recommendations: Echocardiography: twice in } 5 \text { year } \\
\text { Consider review of other risk factors e.g. blood pressure, lipid } \\
\text { measurement. } \\
\text { Risk of hepatic dysfunction } \\
\text { There is a risk of hepatic dysfunction after treatment with } \\
\text { methotrexate } \\
\text { Recommendations: Five years after diagnosis and as clinically } \\
\text { indicated measure liver function tests. Don't repeat if results are } \\
\text { normal. If abnormal, investigate as appropriate, or refer to a } \\
\text { Gastroenterologist. } \\
\text { Osteoporosis } \\
\text { There is a risk of osteoporosis after treatment with corticosteroids } \\
\text { and methotrexate } \\
\text { Recommendations: If clinically indicated X-ray spine and bone } \\
\text { density test }\end{array}$ \\
\hline
\end{tabular}

to complete a health questionnaire about their current health status.

Evaluation of shared care including a web-based survivor care plan

Data on the screening and additional test results were returned by 69 of $72(96 \%)$ family doctors who had seen a survivor for screening. Eleven out of 72 (15\%) family doctors filled in the information in the online form, 61/72 $(85 \%)$ family doctors used the printed form and returned this in the provided stamped addressed envelope. Sixty (83\%) family doctors performed the screening according to the Dutch guidelines, including laboratory tests, pulmonary function tests and echocardiograms; nine family doctors did not perform the complete battery of recommended tests. According to the guidelines, 62 survivors needed laboratory tests, 33 needed an echocardiogram, 16 needed a pulmonary function test and 3 survivors needed a mammography. Missing data included an echocardiogram (4 out of 33 patients who needed echocardiography according to the guidelines), laboratory tests (4/62), mammography $(1 / 3)$ and a pulmonary function test $(1 / 16)$.

Thirteen out of 80 survivors $(16 \%)$ had no late effects, whereas $48 / 80(60 \%)$ had two or more late effects. Thirtyfour out of $80(43 \%)$ had a severe grade 3 or 4 late effect. Most frequent late effects of treatment included: psychosocial problems $(28 / 80,35 \%)$, fertility issues $(19 / 80,24 \%)$, 


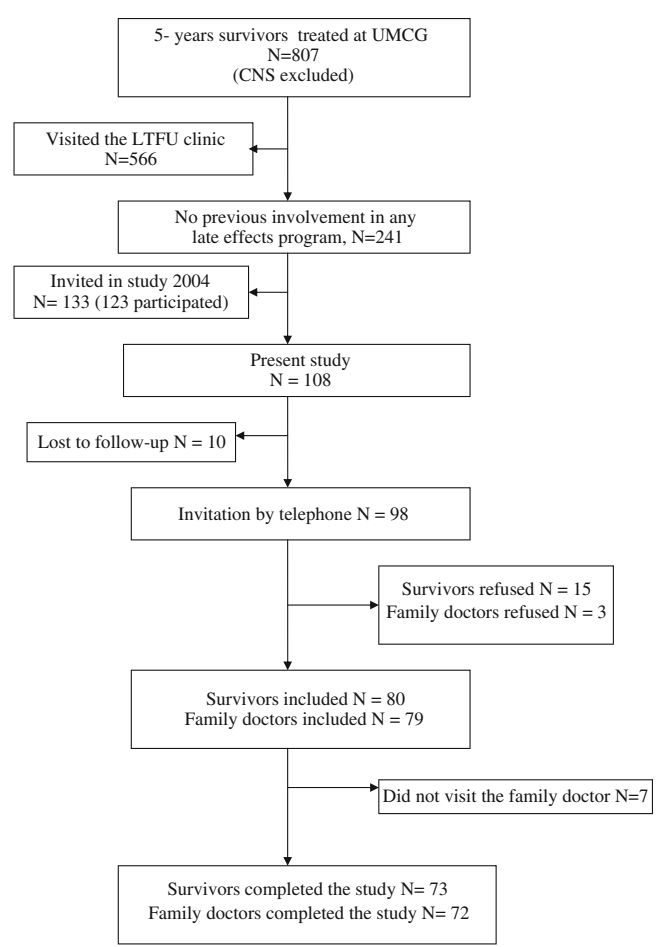

Fig. 2 Study profile

endocrine problems $(16 / 80,20 \%)$, cardiac problems $(13 / 80$, $16 \%)$, orthopaedic problems $(13 / 80,16 \%)$ and neurological

Table 1 Characteristics of included childhood cancer survivors $(N=80)$

Age in years (median, range)

At study

$38(19-56)$

At diagnosis

$9(0-27)$

Time since diagnosis

$29(11-44)$

Type of tumour, number $(\%)$

Leukaemia

$31(39)$

Malignant lymphoma

Bone tumour

13 (16)

Soft tissue sarcoma

3 (4)

Wilms' tumour

7 (9)

Langerhans cell histiocytosis

7 (9)

Other

$11(14)$

Treatment

Radiotherapy

$42(52)$

Cranial radiation

$20(25)$

Chemotherapy

$76(95)$

Bone marrow transplantation

$5(6)$

Risk level (according to Wallace et al. [6])

Level 1

$17(21)$

Level 2

19 (24)

Level 3

$44(55)$

Outcome

Two or more late effects problems $(13 / 80,16 \%)$. Family doctors and survivors merely reported the occurrence of a late effect and not when it was detected; therefore, it is unknown how many of these late effects were newly detected at the follow-up visit and how many were already pre-existent. Eight survivors $(10 \%)$ had a second malignancy. Two of them had a meningioma, one had an intracerebral cavernous haemangioma, one had breast cancer, one had thyroid cancer, one had gastric cancer, one had a basocellular carcinoma and one had a meningioma as well as multiple basocellular carcinomas.

Evaluation of the web-based survivor care plan

The survivors' questionnaire was completed by $72 / 73$ participating survivors (99\%) (Table 2). The vast majority (96\%) had had access to the website and found the SCP user-friendly for both the online and the printed version. About three-quarters (73\%) of them thought their knowledge of late effects had improved through the SCP and nearly all (97\%) survivors had become more aware of the benefits of follow-up. A minority of the survivors (11\%) felt that the provided information was insufficient. Typical comments included 'I lack information about psychological late effects', 'I had expected more information' and 'The language used in the survivorship care plan is too medical'. Most survivors $(82 \%)$ had confidence in the competence of their family doctor to perform the screening. Only two had 'The feeling that my family doctor doesn't take me seriously', and one preferred 'To have check-ups in the late effects clinic and at the family doctor's alternately'. Many survivors (77\%) had experienced reawakened memories of their past illness, and $34 \%$ stated that all the supplied information had worried them.

The questionnaire for family doctors was completed by $53 / 72$ participating family doctors (74\%) (Table 3). Most family doctors $(85 \%)$ had had access to the website; however, $15 \%$ of them experienced difficulties in entering the website, mostly because they had forgotten their password.

The vast majority of family doctors (97\%) found the SCP user-friendly; $83 \%$ felt that their knowledge of late effects and 95\% that their awareness of the benefits of follow-up had improved. Remarkably, 93\% considered themselves capable to perform follow-up care provided that a SCP was available. One of the comments was 'It helps to restore the contact with patients who are cured of cancer'.

\section{Discussion}

This study shows that the availability of a web-based personalised SCP facilitates optimal follow-up care in a 
Table 2 Questionnaire responses from 72/73 participating survivors

\begin{tabular}{|c|c|c|c|c|c|c|}
\hline \multirow[t]{2}{*}{ Evaluation by survivors } & \multicolumn{2}{|c|}{ Agree } & \multicolumn{2}{|c|}{ Disagree } & \multirow{2}{*}{$\begin{array}{l}\text { No opinion } \\
\text { Not applicable } \\
N\end{array}$} & \multirow{2}{*}{$\begin{array}{l}95 \% \text { CI } \\
\text { For agree } \\
\%\end{array}$} \\
\hline & $N$ & $\%$ & $N$ & $\%$ & & \\
\hline \multicolumn{7}{|l|}{ About the website } \\
\hline Could enter the website & 69 & 96 & 3 & 4 & 0 & $88-99$ \\
\hline User-friendly & 59 & 95 & 3 & 5 & 10 & $87-99$ \\
\hline Information is clear & 60 & 95 & 3 & 5 & 9 & $87-99$ \\
\hline Information is sufficient & 55 & 89 & 7 & 11 & 10 & $78-95$ \\
\hline Information fulfils my needs & 53 & 90 & 6 & 10 & 13 & $76-94$ \\
\hline \multicolumn{7}{|l|}{ About the written survivorship care plan } \\
\hline User-friendly & 66 & 97 & 2 & 3 & 4 & $90->99$ \\
\hline Information is clear & 66 & 97 & 2 & 3 & 4 & $90->99$ \\
\hline Information is sufficient & 58 & 84 & 11 & 16 & 3 & $73-92$ \\
\hline Information fulfils my needs & 60 & 90 & 7 & 10 & 5 & $80-96$ \\
\hline \multicolumn{7}{|l|}{ About participation } \\
\hline My knowledge of late effects improved & 47 & 73 & 17 & 27 & 8 & $61-84$ \\
\hline Questions about the past were clarified & 34 & 64 & 19 & 36 & 19 & $50-77$ \\
\hline All this information worries me & 22 & 34 & 43 & 66 & 7 & $23-47$ \\
\hline Reminded me of past illness and experiences & 55 & 77 & 16 & 23 & 1 & \\
\hline Positive & 15 & 27 & & & & \\
\hline Negative & 11 & 20 & & & & \\
\hline Both positive and negative & 29 & 53 & & & & \\
\hline From now on, I will return to my family doctor for late effects follow-up & 50 & 82 & 11 & 18 & 11 & $70-91$ \\
\hline More aware of the benefits of follow-up & 65 & 97 & 2 & 3 & 5 & $90-97$ \\
\hline I have confidence in my family doctor's expertise in performing the screening & 53 & 82 & 12 & 18 & 7 & $70-90$ \\
\hline
\end{tabular}

shared-care model between the late effect outpatient clinic and family doctors. Moreover, the SCP was greatly appreciated by the survivors, who had become more aware of potential risks of health problems and of the benefits of follow-up, as was concluded from the questionnaires. Nearly all family doctors considered themselves capable to perform follow-up care provided that a SCP was available.

Participants were as satisfied with the web-based design as with a written SCP. However, a web-based design has clear advantages in favour of a written summary alone. Firstly, it is accessible at any place or time, provided that an Internet connection is available. Secondly, it ensures the availability of the plan as patients change doctors. Moreover, it allows the flexibility for additional data entry adapted to the individual survivor's needs and condition, and can easily be updated upon new knowledge of late effects and/or renewed guidelines for follow-up. In this way, the SCP can be kept up-to-date very easily. Finally, a web-based SCP is unlikely to be lost compared to a written version.

Other authors have advocated the use of a SCP [12-15, $17,19,21]$ in survivors of cancer and some advocate an electronic version $[12,13]$. In its report on care for adult cancer survivors 'From Cancer Patient to Cancer Survivor: Lost in Transition', the Institute of Medicine also strongly recommended the provision of a SCP and considered it necessary for ongoing clinical care of survivors [22]. It was stated that a SCP might help patients share in the responsibility for their health care and help to ensure appropriate follow-up care. However, despite these recommendations, reports on application of a SCP in survivors of adult cancer are scarce. Miller et al. [16] reported a pilot study on five breast cancer survivors and found that SCPS provided practical guidance for survivors by organising the requirements of follow-up and that is was helpful for patient empowerment. Burg et al. [12] conducted four focus group studies with breast cancer survivors who were asked their opinions on the value and content of a survivorship care plan. They concluded that among survivors, there was general enthusiasm for the concept of a SCP. Similar findings resulted from focus group studies performed by Hewitt et al. [13] in survivors of various other types of adult cancers. These survivors expressed a great interest in having a personalised SCP presented in layman's terms, including attention to their psychological needs. Educational websites for survivors such as the new DCOG LATER 
Table 3 Questionnaire responses from 53/72 participating family doctors

\begin{tabular}{|c|c|c|c|c|c|c|}
\hline \multirow[t]{2}{*}{ Evaluation by family doctors } & \multicolumn{2}{|l|}{ Agree } & \multicolumn{2}{|c|}{ Disagree } & \multirow{2}{*}{$\begin{array}{l}\text { No opinion } \\
\text { Not applicable } \\
N\end{array}$} & \multirow{2}{*}{$\begin{array}{l}95 \% \text { CI } \\
\text { For agree } \\
\%\end{array}$} \\
\hline & $N$ & $\%$ & $N$ & $\%$ & & \\
\hline \multicolumn{7}{|l|}{ About the website } \\
\hline Could enter the website & 45 & 85 & 8 & 15 & 0 & $72-93$ \\
\hline User-friendly & 36 & 97 & 1 & 3 & 16 & $86->99$ \\
\hline Information is clear & 39 & 100 & 0 & 0 & 14 & $91-100$ \\
\hline Information is sufficient & 39 & 100 & 0 & 0 & 14 & $91-100$ \\
\hline Information fulfils my needs & 37 & 100 & 0 & 0 & 16 & $91-100$ \\
\hline \multicolumn{7}{|l|}{ About the written survivorship care plan } \\
\hline User-friendly & 48 & 100 & 0 & 0 & 5 & $93-100$ \\
\hline Information is clear & 48 & 100 & 0 & 0 & 5 & $93-100$ \\
\hline Information is sufficient & 48 & 100 & 0 & 0 & 5 & $93-100$ \\
\hline Information fulfils my needs & 47 & 98 & 1 & 2 & 5 & $89-100$ \\
\hline \multicolumn{7}{|l|}{ About participation } \\
\hline My knowledge of late effects improved & 38 & 83 & 8 & 17 & 7 & $69-92$ \\
\hline Do you think memories of past illness and experiences were recalled by your patient? & Yes, 27 & 63 & No, 16 & 37 & 10 & \\
\hline Positive & 0 & 0 & & & & \\
\hline Negative & 8 & 20 & & & & \\
\hline Both positive and negative & 19 & 43 & & & & \\
\hline More aware of the benefits of follow-up & 42 & 95 & 2 & 5 & 9 & $85-99$ \\
\hline Able to perform follow-up care if a survivorship care plan is available & 41 & 93 & 3 & 7 & 9 & $81-99$ \\
\hline
\end{tabular}

patient information website (http://later.skion.nl) [23] and templates for creation of a SCP on the Internet have been developed by several groups [14, 24]. However, survivors who want to create an individualized SCP by themselves, for instance through Oncolife (http://www.oncolink.org/ oncolife), need detailed information on their cancer diagnosis and treatment. It can be questioned whether the average survivor is aware of treatment details like names and doses of cytostatic drugs, type, dose and field of irradiation and surgery details. Also, it has been shown that adult survivors of childhood cancer have significant knowledge deficits regarding their disease and treatment $[25,26]$. If the data on which SCPs are created are strictly based on user responses and not verified by a medical professional, there is a considerable risk that the information supplied will be incorrect or incomplete.

Oeffinger et al. [19] recently published a study that is comparable with ours; however, there are some fundamental differences. They also found that a mailed personalised survivorship care plan was effective in communicating risk and increasing compliance with recommended medical surveillance among high-risk survivors of childhood Hodgkin lymphoma. A fundamental difference between Oeffinger's study and ours is that in our study, the survivors could only participate if they agreed to make an appointment at the family doctor's practice for a late effect-related visit, while in the study of Oeffinger and colleagues, survivors were encouraged to discuss the information from the SCP that they had received by mail, with the family doctor. However, only half of the participating survivors $(29 / 55,53 \%)$ actually visited their family doctor, which is far less than the $73 / 80$ (91\%) survivors in our study. In Oeffinger's study, financial restrictions could be a barrier for the survivors to visit the family doctor for the recommended follow-up care, whereas in The Netherlands, almost everyone has health care access through a national health plan. Moreover, Dutch health insurances refund the recommended follow-up screening. Both Oeffinger's study and ours show that when the survivors presented the information to the family doctor, the requested surveillance tests were ordered.

In contrast to the study of Oeffinger et al. [19], who found no increase in anxiety following risk notification, in our study $34 \%$ of the survivors stated that the provided information had worried them. Negative consequences of long-term follow-up have also been described before, such as increased anxiety and being stigmatised as 'a patient', in contrast to the benefits of follow-up, namely early detection of late effects [27]. However, without information and education of survivors, the quality of long-term follow-up care may be suboptimal. The advantages and disadvantages of long-term follow-up, including the provision of a SCP, must be weighed carefully. In our study, $15 \%$ of eligible survivors refused participation; a survey of their motives would be worthwhile. 
Other barriers for SCPs exist, such as preparation time involved for busy clinicians as well as lack of research related to care plans and patient outcomes $[15,16]$. In our study, the creation of the SCP required hardly any preparation time as data on diagnosis, treatment and potential risks could be retrieved from the database register automatically. However, the availability of a complete and up-to-date database remains a prerequisite. In addition, the availability of recently completed Dutch national guidelines for the long-term follow-up of childhood cancer survivors enabled us to add personalised recommendations for follow-up and healthy lifestyle.

The questionnaire responses showed that the vast majority of the participating family doctors in our study considered themselves competent to participate in the care of long-term childhood cancer survivors, if a SCP is made available. This is supported by the results of patient encounters, as $83 \%$ of the family doctors had completed the recommended tests as included in the SCP and had returned the results to the late effects clinic. These results are the more remarkable given that $55 \%$ of CCS were categorized as level 3 patients with a high risk of developing serious late effects, who, according to Wallace et al. [6], should have been in annual follow-up from a medically supervised late effects clinic. Level 3 survivors benefit less from follow-up by primary care providers because they often require referral to a specialist for additional tests such as pulmonary function tests or echocardiography. Most family doctors stated that their knowledge of the survivor's health status had improved as well as their knowledge of late effects. This is an important achievement, as it makes family doctors aware of a possible relation with the cancer history if a survivor seeks medical help. This could be particularly beneficial for level 3 patients with a high risk for complex health problems.

Until now, in our study, a key role was allotted to an academic family doctor (RB) with an interest in late effects of treatment. This family doctor is fully aware of current general practice, its possibilities and its limitations. Once the piloting stage has been finished, this role probably could be taken over by a dedicated oncology nurse or nurse practitioner.

Although the majority of survivors greatly appreciated the SCP, 1 out of 10 was not satisfied, commenting that the language used in the SCP was too technical and that the information did not meet their expectations, particularly regarding psychosocial issues. These issues must be addressed in a subsequent version of the SCP.

A limitation of our study is that the number of participants is rather small. The questionnaires that were used for the evaluation were anonymous, as we expected that anonymity would increase the response rate. Because of this anonymity, it was not possible to compare satisfaction rates between the three risk groups. Another matter of concern is the fact that $15 \%$ of the participating family doctors stated that they could not enter the website, mostly because they had forgotten the password and only $15 \%$ of the family doctors filled in the information in the online screening form. Therefore, besides the possibility to exchange information online, there is still a need to use a printed version of the SCP and screening forms with a stamped addressed envelope.

We conclude that a web-based SCP can serve as an effective communication vehicle between the survivor, the family doctor and the long-term outpatient clinic to provide follow-up care by family doctors.

Acknowledgements The authors are indebted to Ilora Finley, professor of palliative medicine, Cardiff University, UK for her useful comment and critical reading of the manuscript, and to Paul Koenes and Jef Everts (UMCG, The Netherlands) for their technical assistance and the design of the website.

Role of funding sources The study was funded by the University Medical Center Groningen, The Netherlands, and the NutsOhra fund. The development of the website was funded by Friesland Zorgverzekeraar. The sponsors had no role in the study design, data collection, data analysis, interpretation or writing of the report.

Conflicts of interest statement The authors declared no conflicts of interest.

Open Access This article is distributed under the terms of the Creative Commons Attribution Noncommercial License which permits any noncommercial use, distribution, and reproduction in any medium, provided the original author(s) and source are credited.

\section{References}

1. Oeffinger KC, Mertens AC, Sklar CA, et al. Chronic health conditions in adult survivors of childhood cancer. N Engl J Med. 2006;12:1572-82.

2. Blaauwbroek R, Groenier KH, Kamps WA, et al. Late effects in adult survivors of childhood cancer: the need for life-long followup. Ann Oncol. 2007;18:1898-902.

3. Geenen MM, Cardous-Ubbink MC, Kremer LC, et al. Medical assessment of adverse health outcomes in long-term survivors of childhood cancer. JAMA. 2007;27:2705-15.

4. Goldsby RE, Ablin AR. Surviving childhood cancer; now what? Controversies regarding long-term follow-up. Pediatr Blood Cancer. 2004;43:211-4.

5. Friedman DL, Freyer DR, Levitt GA. Models of care for survivors of childhood cancer. Pediatr Blood Cancer. 2006;46:159-68.

6. Wallace WH, Blacklay A, Eiser C, et al. Developing strategies for long term follow up of survivors of childhood cancer. BMJ. 2001;4:271-4.

7. Oeffinger KC, Mertens AC, Hudson MM, et al. Health care of young adult survivors of childhood cancer: a report from the childhood cancer survivor study. Ann Fam Med. 2004;2:61-70.

8. Grunfeld E, Mant D, Yudkin P, et al. Routine follow up of breast cancer in primary care: randomised trial. BMJ. 1996;14:665-9. 
9. Agboola OO, Grunfeld E, Coyle D, Perry GA. Costs and benefits of routine follow-up after curative treatment for endometrial cancer. CMAJ. 1997;1:879-86.

10. Dancey A, Rayatt S, Courthold J, Roberts J. Views of UK melanoma patients on routine follow-up care. Br J Plast Surg. 2005;58:245-50.

11. Blaauwbroek R, Tuinier W, Meyboom-de JB, et al. Shared care by paediatric oncologists and family doctors for long-term follow-up of adult childhood cancer survivors: a pilot study. Lancet Oncol. 2008;9:232-8.

12. Burg MA, Lopez ED, Dailey A, et al. The potential of survivorship care plans in primary care follow-up of minority breast cancer patients. J Gen Intern Med. 2009;24 Suppl 2:S467-71.

13. Hewitt ME, Bamundo A, Day R, Harvey C. Perspectives on posttreatment cancer care: qualitative research with survivors, nurses, and physicians. J Clin Oncol. 2007;1:2270-3.

14. Houlihan NG. Transitioning to cancer survivorship: plans of care. Oncology (Williston Park). 2009;23 Suppl 8:42-8.

15. Earle CC. Failing to plan is planning to fail: improving the quality of care with survivorship care plans. J Clin Oncol. 2006;10:5112-6.

16. Miller R. Implementing a survivorship care plan for patients with breast cancer. Clin J Oncol Nursing. 2008;12:479-87.

17. Ganz PA, Casillas J, Hahn EE. Ensuring quality care for cancer survivors: implementing the survivorship care plan. Semin Oncol Nurs. 2008;24:208-17.

18. van de Poll-Franse LV, van Eenbergen MC. Internet use by cancer survivors: current use and future wishes. Support Care Cancer. 2008;16:1189-95.
19. Oeffinger KC, Hudson MM, Mertens AC. Increasing rates of breast cancer and cardiac surveillance among high-risk survivors of childhood Hodgkin lymphoma a mailed, one-page survivorship care plan. Pediatr Blood Cancer. 2010;56:818-24.

20. Trotti A, Colevas AD, Setser A, et al. CTCAE v3.0: development of a comprehensive grading system for the adverse effects of cancer treatment. Semin Radiat Oncol. 2003;13:176-81.

21. Gilbert SM, Miller DC, Hollenbeck BK, et al. Cancer survivorship: challenges and changing paradigms. J Urol. 2008;179:431-8.

22. Hewitt M, Greenfield S, Stovall E. From cancer patient to cancer survivor: lost in transition. Washington, DC: National Academies Press; 2006.

23. Knijnenburg SL, Kremer LC, van den Bos C, et al. Health information needs of childhood cancer survivors and their family. Pediatr Blood Cancer. 2010;54:123-7.

24. Hill-Kayser CE, Vachani C, Hampshire MK, et al. An internet tool for creation of cancer survivorship care plans for survivors and health care providers: design, implementation, use and user satisfaction. J Med Internet Res. 2009;11(3):e39.

25. Bashore L. Childhood and adolescent cancer survivors' knowledge of their disease and effects of treatment. J Pediatr Oncol Nurs. 2004;21:98-102.

26. Kadan-Lottick NS, Robison LL, Gurney JG, et al. Childhood cancer survivors' knowledge about their past diagnosis and treatment: childhood cancer survivor study. JAMA. 2002;10:1832-9.

27. Pennery E, Mallet J. A preliminary study of patients' perceptions of routine follow-up after treatment for breast cancer. Eur J Oncol Nurs. 2000;4:138-45. 